\title{
Effect of Post Weld Heat Treatment on Microstructures and Mechanical Properties of AZ31B Friction Welded Joint
}

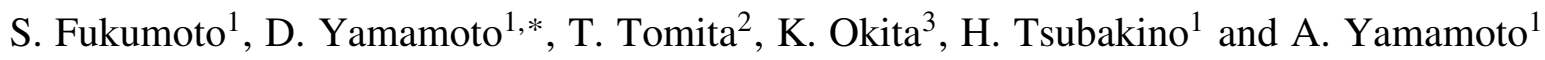 \\ ${ }^{1}$ Graduate school of Engineering, University of Hyogo, Himeji 671-2201, Japan \\ ${ }^{2}$ Hyogo prefectural institute of technology, Kobe 654-0037, Japan \\ ${ }^{3}$ Osaka Sangyo University, Daito 574-8530, Japan
}

\begin{abstract}
AZ31 magnesium alloy was welded by friction welding and the effect of post weld heat treatment on microstructures and mechanical properties were investigated. Fine grained microstructure whose minimum grain size is approximately $1 \mu \mathrm{m}$ was formed at the weld interface by dynamic recrystallization due to hot-heavy working. Although abnormal grain growth which is often found in stir zone in friction stir welding occurred near weld interface where the material was work hardened, the area was limited and did not affect the mechanical properties of weld interface. The tensile and fatigue strength of as weld joints were equal to those of base metal and did not decrease until grain size increased to approximately $15 \mu \mathrm{m}$. The decrease in the Hall-Petch slope was found when the grain size decreased less than $3 \mu \mathrm{m}$ in grain size in terms of yield stress. [doi:10.2320/matertrans.48.44]
\end{abstract}

(Received August 15, 2006; Accepted November 13, 2006; Published December 25, 2006)

Keywords: friction welding, magnesium alloy, Hall-Petch relation, abnormal grain growth, post weld heat treatment

\section{Introduction}

Magnesium alloys are attractive for automotive industry due to their high specific strength. Reliable joining technique is needed to build up structures with magnesium alloys. However, since magnesium is one of the most active metals, conventional fusion welding process such as GTAW often results in defect and require severe controlled atmosphere. Recently, friction stir welding (FSW) which is believed to be operated in solid state achieves a successful outcome on joining of aluminum or magnesium alloys. ${ }^{1-3)}$ One of the specific microstructural features on friction stir zone is grain refinement ${ }^{3,4)}$ which is caused by hot-heavyworking in solid state, resulting in additional valuable mechanical properties in some cases. On the other hand, the fine grained microstructure of stir zone is unstable at elevated temperature in comparison with normal microstructure. It has been reported abnormal grain growth occurred in the stir zone of friction stir welded aluminum alloys. ${ }^{5,6)}$

Friction welding is a more classic process than FSW in terms of use of friction phenomenon. Therefore, many researches have been published on mechanical properties, $\left.{ }^{7,8}\right)$ microstructures, ${ }^{9,10)}$ modeling, ${ }^{11)}$ welding temperature estimation $^{12,13)}$ and so on in wide variety of materials from steels to ceramics. However, lack of published works on effect of post weld heat treatment (PWHT) will be a serious problem in near future. This is because the feature of microstructure of friction welding is also grain refinement that is caused by similar mechanism to FSW, that is, dynamic recrystallization. ${ }^{9}{ }^{10)}$ However, the grain growth behavior of friction weld joint has not been studied yet. So it is necessary to investigate thermal stability of microstructures made by friction welding.

Moreover, it is well known that formability of magnesium

*Undergraduate Student, Himeji Institute of Technology (University of Hyogo) is poor because of its hcp crystal structure. One of the solutions must be a grain refinement. In terms of the effect of grain size on mechanical properties of magnesium alloys, some different results were reported. Park et al. found classical Hall-Petch relation about hardness in friction stir welded magnesium alloy. ${ }^{1)}$ On the other hand, Wilson reported $0.1 \%$ proof stress of pure magnesium decreased with decreasing grain size after reaching peak value. ${ }^{14)}$ Since fine grained microstructure is also obtained by friction welding, ${ }^{9,10)}$ magnesium alloys with wide variety of grain size would be produced by PWHT.

In the present study, the effect of PWHT on microstructures and mechanical properties of friction welded magnesium alloy is investigated. Beside, the relation between grain size and mechanical properties of magnesium alloy is also described.

\section{Experimental Procedures}

The material used in the present study was hot extruded AZ31B magnesium alloy bar whose diameter was $19 \mathrm{~mm}$. The material was worked for the welding as shown in Fig. 1 and the faying surface was cleaned with acetone prior to the welding. The chemical composition is shown in Table 1 . The optimum welding condition, $70 \mathrm{MPa}$ of friction

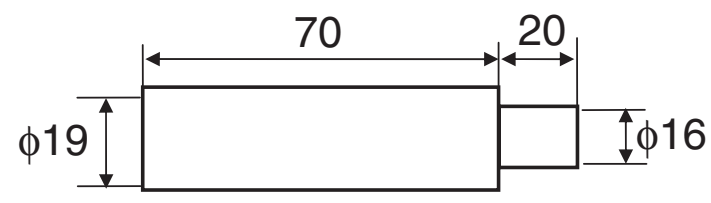

Fig. 1 Geometry of specimen for friction welding. (unit: mm)

Table 1 Chemical compositions of AZ31B (mass\%).

\begin{tabular}{cccccccc}
\hline $\mathrm{Al}$ & $\mathrm{Zn}$ & $\mathrm{Mn}$ & $\mathrm{Fe}$ & $\mathrm{Si}$ & $\mathrm{Ni}$ & $\mathrm{Cu}$ & $\mathrm{Mg}$ \\
\hline 3.17 & 0.88 & 0.26 & 0.0010 & 0.0008 & 0.0040 & 0.0200 & Bal. \\
\hline
\end{tabular}




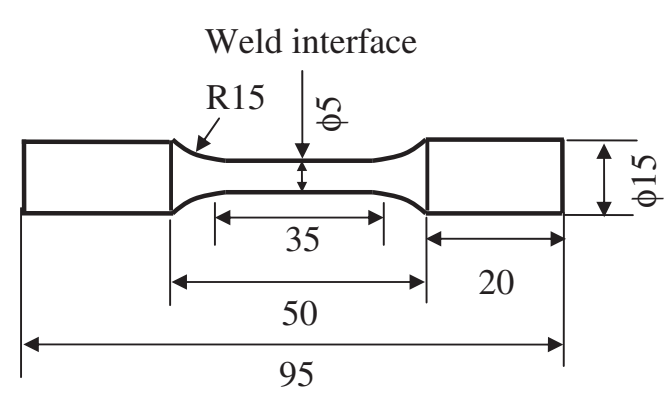

(a)

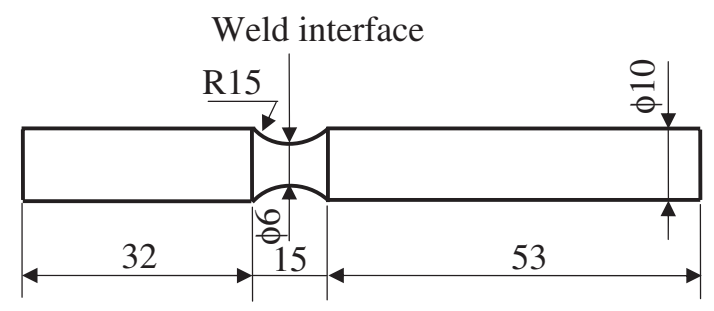

(b)

Fig. 2 Geometry of specimens for tensile test (a), and fatigue test (b), (unit: $\mathrm{mm}$ ).

pressure, $140 \mathrm{MPa}$ of upset pressure, $0.5 \mathrm{~s}$ of friction time, $6.0 \mathrm{~s}$ of upset pressure and $2000 \mathrm{rpm}$ of rotational speed, was adopted to obtain a sound joint after cautious preliminary tests. The friction welded joints were heat treated at 473, 573,673 and $773 \mathrm{~K}$ for 0.9 to $72.0 \mathrm{ks}$. The effect of PWHT conditions on the microstructures was investigated by an metallographic examination using optical microscopy. Before examination, the mechanically polished surface was chemically etched with standard etchant of acetic picral. Grain size was measured as a circle equivalent diameter on optical micrographs by the image analysis software, win ROOF.

Tensile tests were carried out with the condition of $0.017 \mathrm{~mm} / \mathrm{s}$ in cross-head speed. The geometry of specimens are shown in Fig. 2. Strain at the weld interface was measured by a strain gage whose gage length was $1 \mathrm{~mm}$. The fatigue test was carried out by the rotating fatigue test machine which was fabricated by Seimitsu Kogyo LTD. The rotation speed of the fatigue test was $3000 \mathrm{rpm}$. Micro Vickers hardness was also measured near the weld interface with the load of $0.49 \mathrm{~N}$.

\section{Results}

\subsection{As weld joint}

Optical microstructures along a central axis of coupon in as weld joint are shown in Fig. 3. Microstructure was changed continuously from the weld interface to the end of workpiece. Microstructures by friction welding consist of mainly three regions which are fine grained region (Fig. 3(a), work hardened region (Figs. 3(b) and 3(c)) and heat affected zone (HAZ) (Fig. 3(d)). The former two regions are like thermomechanically affected zone (TMAZ) which is often named in FSW. Fine grained region was formed by heavy working at high temperature that is close to melting point, resulting in formation of recrystallized fine equiaxed grains with few dislocations. ${ }^{10)}$ Finally, mean grain size of $1.1 \mu \mathrm{m}$ was achieved at the center of weld interface. On the other hand, a lot of shear bands were introduced and relatively large grains that used to be included in base metal were separated by them there (Fig. 3(b)). Besides, grain boundaries became jaggy in the work hardened region where is several mm away from the weld interface. Although work hardened as well as fine grained region is in TMAZ, much more dislocations were introduced in the work hardened region due to deformation at lower temperature. New fine grains were born at the shear bands by dynamic recrystallization. Figure 3(e) shows the microstructure of base metal. Although microstructure of HAZ is similar to that of base metal (Fig. 3(d)), grain growth behavior was different from that of base metal. The details will be discussed later. Grain size at the peripheral region of weld interface where is near the flash is slightly larger than that of the central region. Moreover, grain size increased with friction time. The details of effect of welding parameters on grain size were described in the previous paper. ${ }^{10)}$

Micro-Vickers hardness distribution along the rotational axis near the weld interface is shown in Fig. 4 and mean grain size at each position is shown in the plot. Hardness near the weld interface is larger than that of base metal. The peak value of hardness is found at the work hardened region where is located approximately 3 to $6 \mathrm{~mm}$ away from the weld interface. The additional hardness is caused by either grain refinement or work hardening. Since in the case of friction welding, recrystallized fine grains at the weld interface contain few dislocations, ${ }^{9,10)}$ the additional hardness at the weld interface is due to the grain refinement. On the other hand, grain size at the work hardened region is similar to the base metal. So the additional hardness there is caused by work hardening.

\subsection{Microstructural development by PWHT}

Figure 5 shows the microstructures at the weld interface before and after heat treatment at $573 \mathrm{~K}$. Abnormal grain growth was found at the peripheral region near flash as well as stir zone in friction stir welding. Generally, the abnormal or drastic grain growth is caused by some reasons such as texture, prior deformation, residual stress, surface effect, precipitation phenomenon. The mechanism of abnormal grain growth in the friction welding is probably similar to that of FSW. Hassan et al. reported that the pinning particles would relate to microstructural stability of stir zone in FSWed AA7010 aluminum alloy. ${ }^{15)}$ Sato et al. reported that drastic grain growth was not simple grain growth but accompanied nucleation and growth of newly formed grains, which related to inhomogeneous distribution of stored strain and crystallographic orientation. ${ }^{16)}$ However, it has not been clarified completely yet. In the present study, no significant difference of Vickers hardness was found between central (HV77) and peripheral region (HV74) at the weld interface. On the other hand, mean grain size at the peripheral region at the weld interface was $2.6 \mu \mathrm{m}$, which is larger than that at central region $(1.1 \mu \mathrm{m})$. The peripheral region showed similar hardness to that at central region despite of larger grain size. So in the case of friction welding, inhomogeneous prior deformation might be one of 

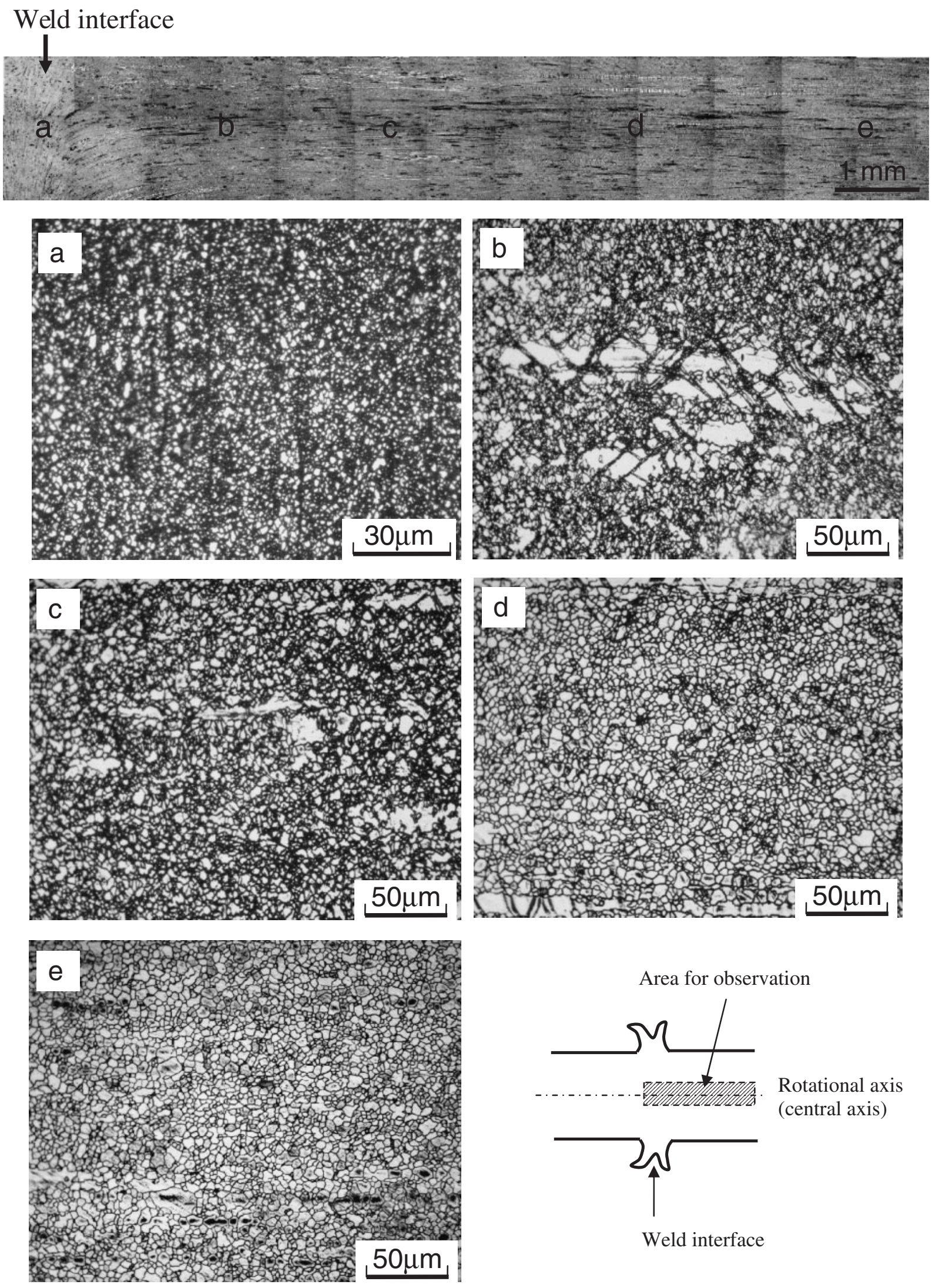

Area for observation

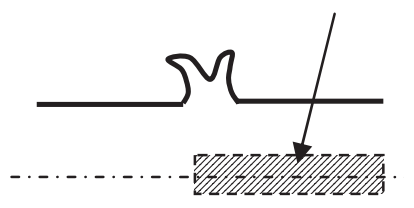

Rotational axis (central axis)

Fig. 3 Microstructural transition from weld interface (a) to base metal (e) of as-weld joint.

the reasons for the abnormal grain growth. In addition, since AZ31B includes second phase such as $\mathrm{Al}_{6} \mathrm{Mn}$, pinning effect would be considered. Anyway, further works on dislocation density and crystallographic orientation are necessary to clarify the abnormal grain growth mechanism in friction welded joint. However, the abnormal grain 


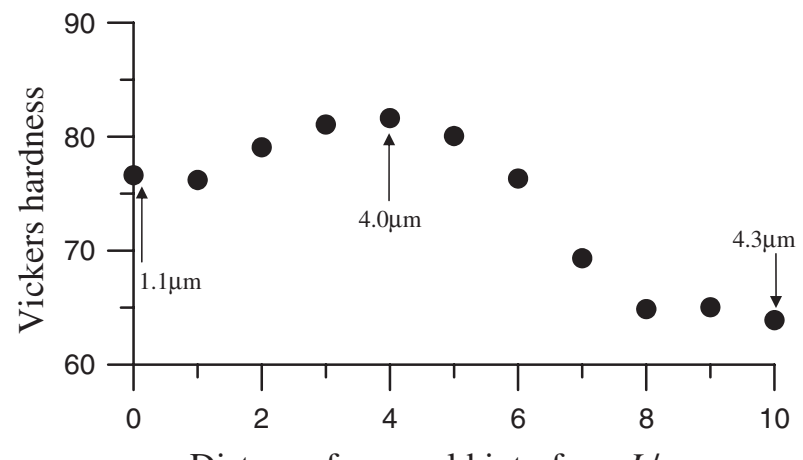

Distance from weld interface, $L / \mathrm{mm}$

Fig. 4 Micro Vickers hardness near weld interface; Mean grain size at each position is shown in the graph.

growth area was limited and did not extend much at the higher temperature. Since the joints were worked for the tensile and fatigue tests as shown in Fig. 2, the influence of peripheral region on the mechanical properties must be negligible. So in the present study, we focused on just central region at the weld interface.

Figures 6 and 7 show the microstructural transition from weld interface to base metal along the central axis. As grain growth progressed, microstructure at each region changed from mixed grain to homogeneous. Two types of grain growth rate were found at each region. Faster grain growth like abnormal grain growth was observed in both work hardened region and base metal (Figs. 6(c) and 6(e)). When the base metal which is extruded bar was annealed, Vickers hardness decreased from HV65 to HV55. So the base metal already has additional hardness due to large dislocation density. The work hardened region could also contain lots of dislocations. Although the difference of dislocation density between base metal and the work hardened region has not been observed, the faster grain growth probably concerns to the effect of prior deformation and residual stress. ${ }^{17)}$ On the other hand, faster grain growth was not observed in fine
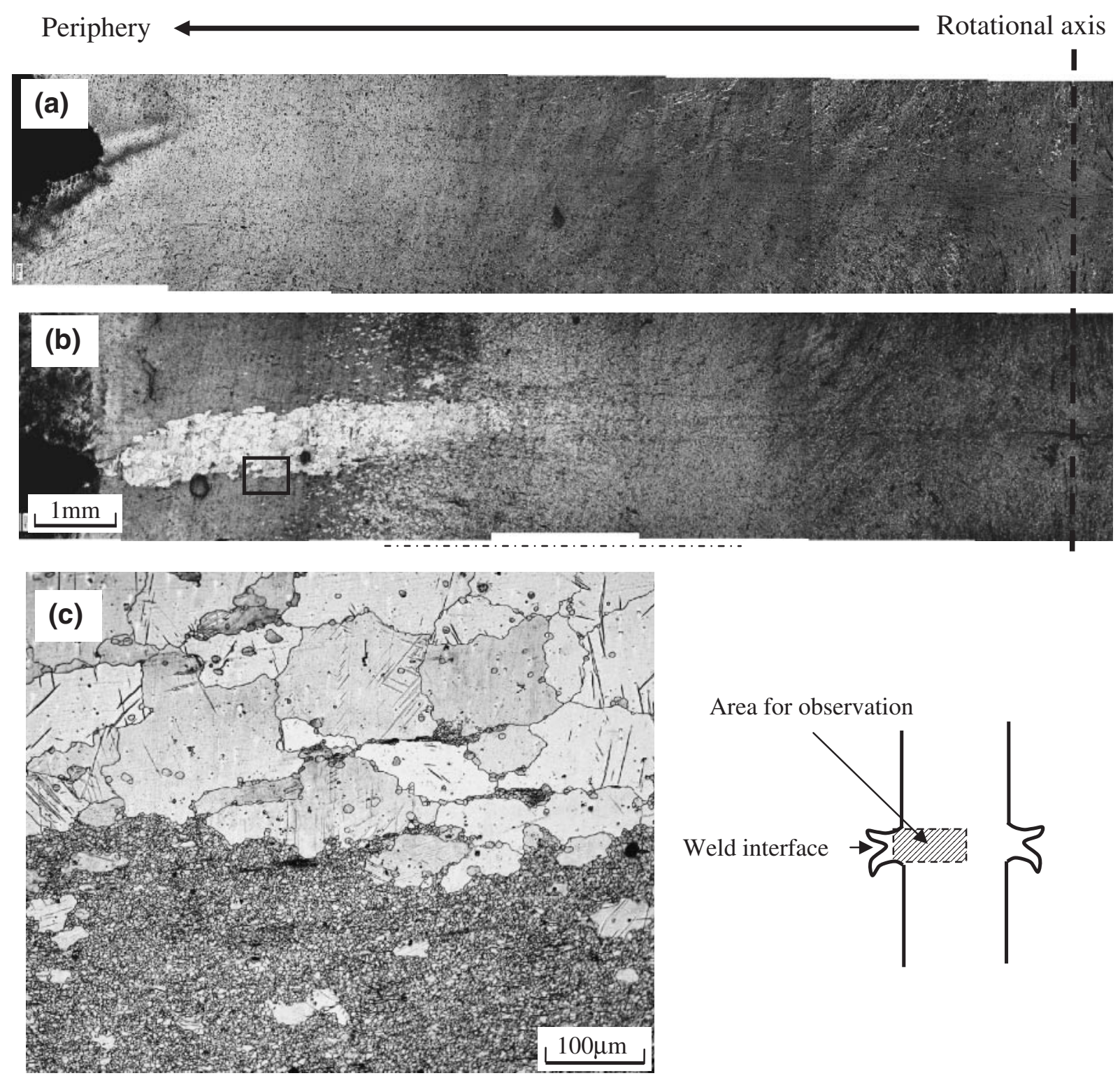

Area for observation

Weld interface

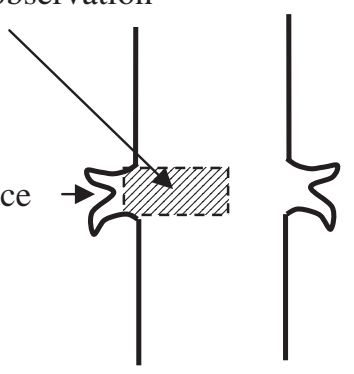

Fig. 5 Abnormal grain growth at peripheral region by post weld heat treatment for $1.8 \mathrm{ks}$ at $573 \mathrm{~K}$; (a) as weld joint, (b) PWHT joint and (c) highlighted region of (b). 

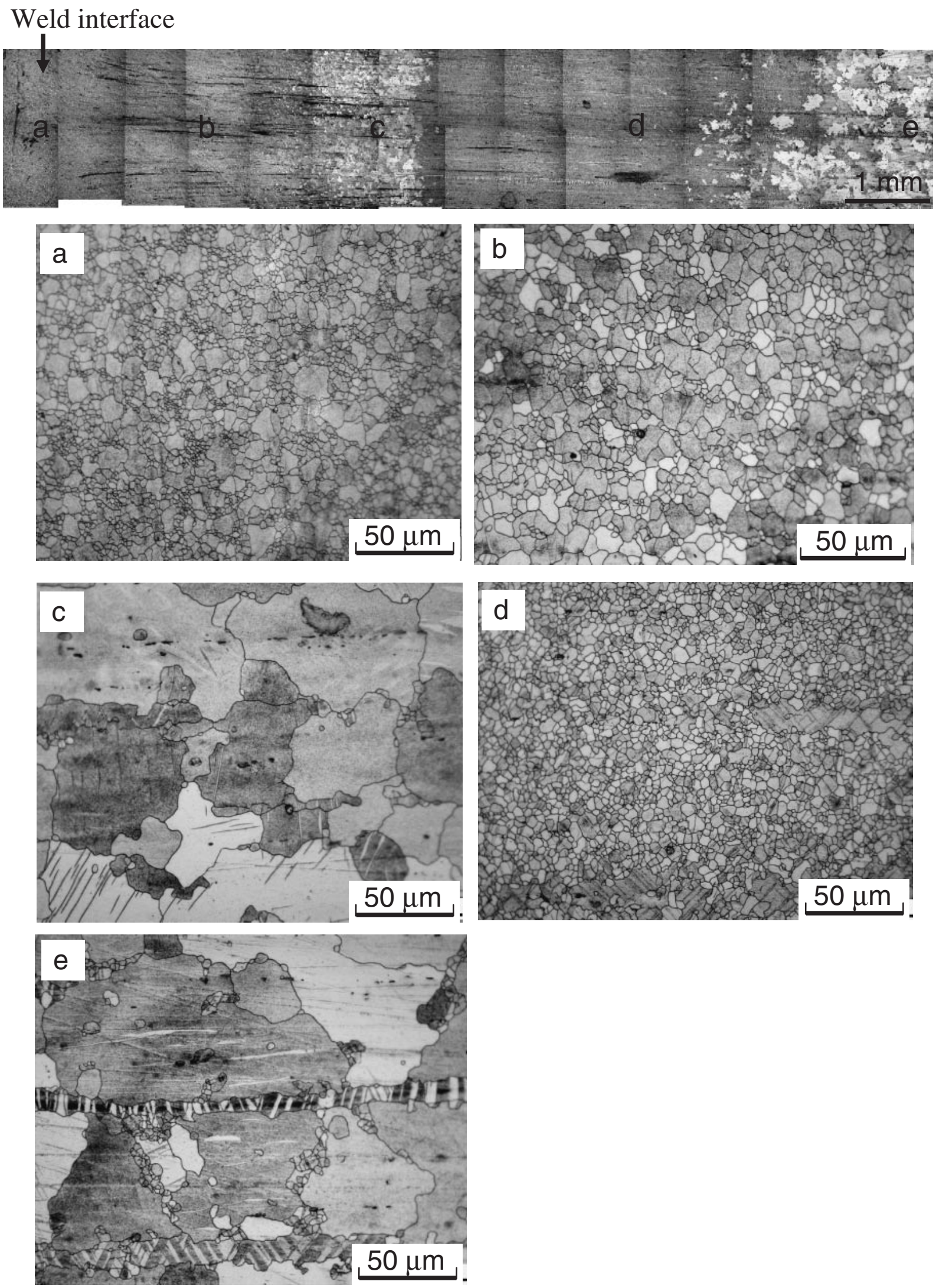

Fig. 6 Microstructural transition from weld interface (a) to base metal (e) of heat treated joint for $1.8 \mathrm{ks}$ at $573 \mathrm{~K}$.

grained region and HAZ (Figs. 6(a) and 6(d)). Fine grained region and HAZ contained few dislocations. Since static recovery has already been completed in HAZ, normal grain growth occurred in spite of similar optical microstructure to base metal (Figs. 3(d) and 3(e)).

Figure 8 shows the plot of mean grain size at the center of 

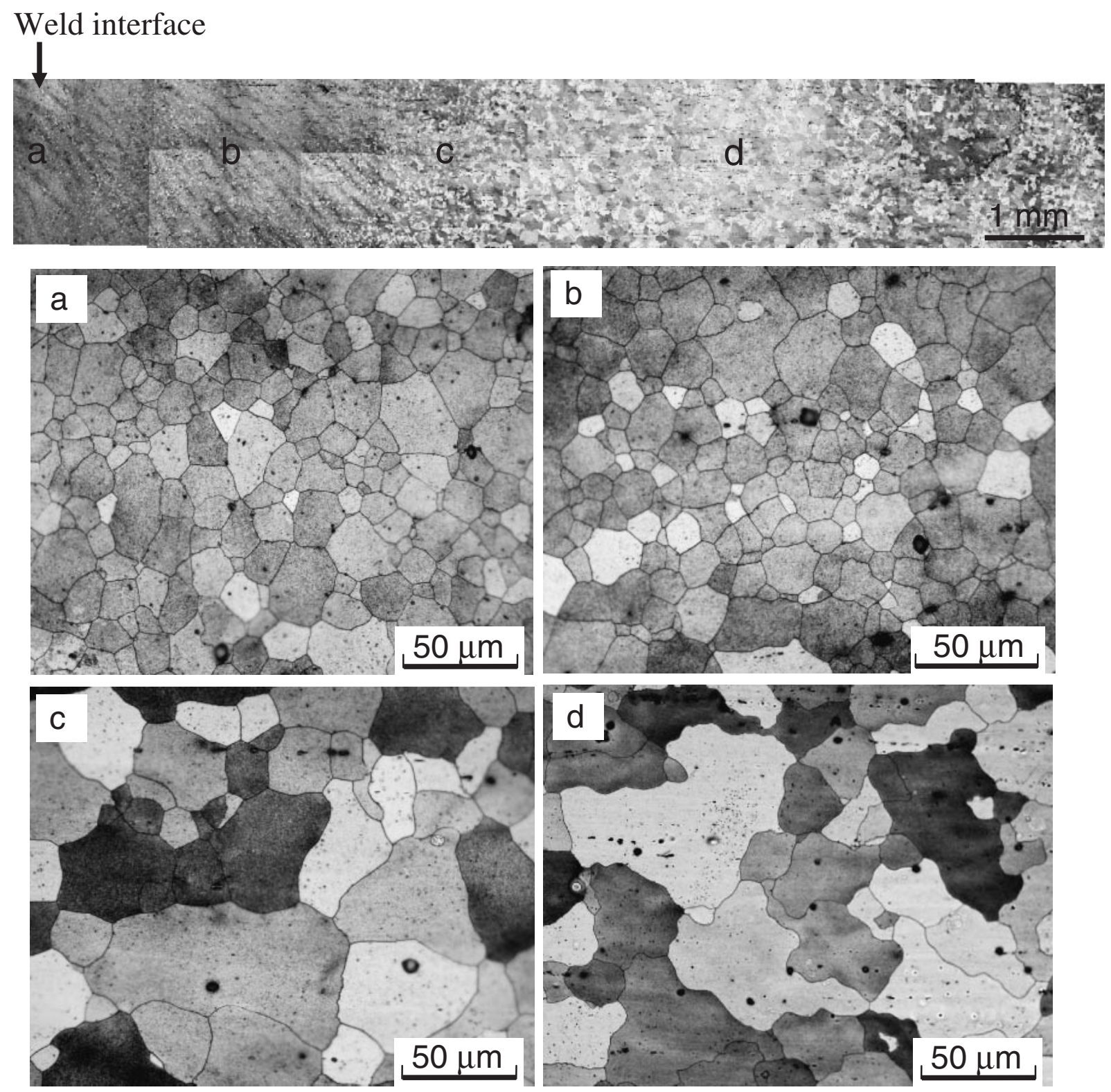

Fig. 7 Microstructural transition from weld interface (a) to base metal (e) of heat treated joint for $7.2 \mathrm{ks}$ at $773 \mathrm{~K}$.

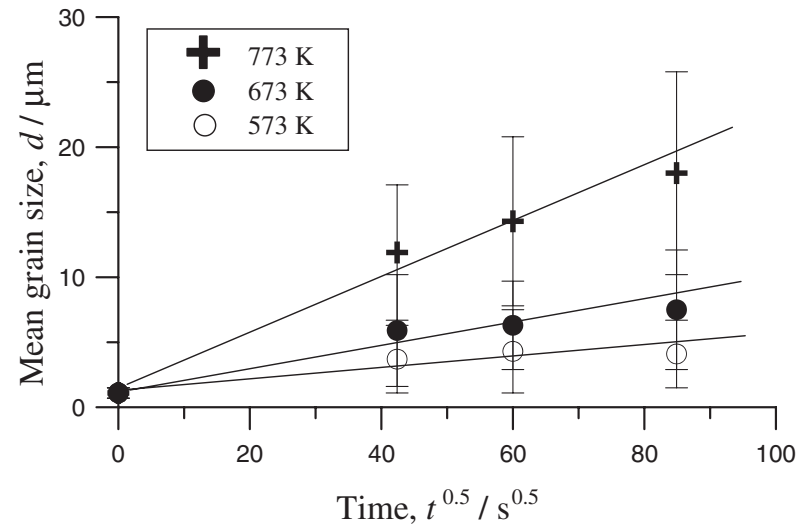

Fig. 8 Grain growth at the center of joint as a function of time at different temperature. weld interface as a function of heat treatment time. At the center of weld interface, mean grain size shows linear relation against the square root of time, which means normal grain growth occurs there. Although central region at the weld interface is a part of TMAZ in friction welding, the behavior of grain growth is different from that of stir zone of FSW. Park et al. reported the stir zone of friction welded magnesium alloy had fine equiaxed grains with a high density of dislocations. ${ }^{1)}$ Moreover, Shibayanagi et al. concluded the effect of residual stress introduced by a shoulder of FSW prove should be considered to discuss abnormal grain growth in a stir zone. ${ }^{17)}$ The difference of dislocation density and residual stress might be the reason why abnormal grain growth did not occur in the fine grained region of friction weld joint.

As a result, grain size could be controlled by heat treatment following friction welding although the area was very limited, that is, weld center. 


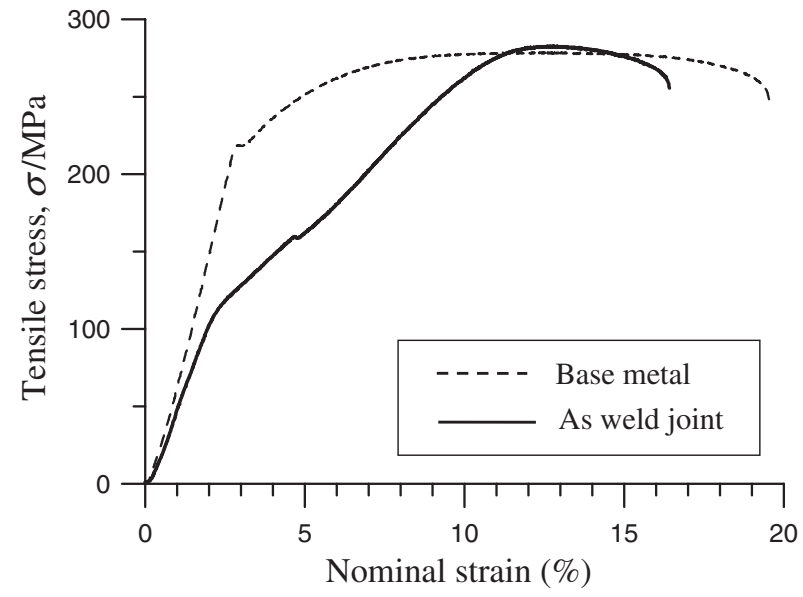

Fig. 9 Stress-strain curves of AZ31B base alloy and as-weld joint.

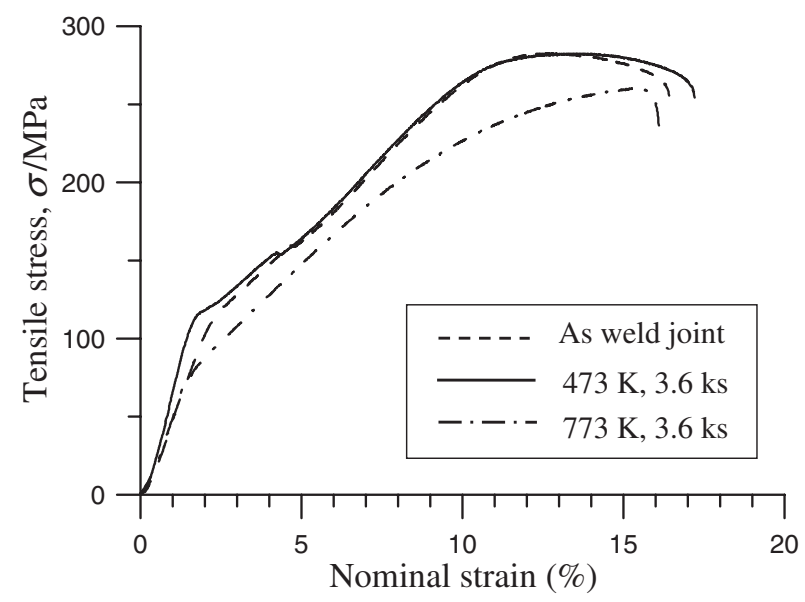

Fig. 10 Stress-strain curves of as-weld joint and heat treated joints.

\subsection{Mechanical properties}

Figures 9 and 10 show typical stress stain curves of base alloy, as weld joint and heat treated joints. Table 2 shows tensile strength, $0.2 \%$ proof stress, mean grain size at the weld interface, and fracture location. $0.2 \%$ proof stress was measured by strain gage at the weld interface. As weld joint was fractured in base metal and showed $100 \%$ joint efficiency although yield strength was decreased. Tensile strength was not affected by PWHT except for a joint made with $773 \mathrm{~K} /$ $3.6 \mathrm{ks}$. The additional strength due to work hardening was removed by heat treatment of $773 \mathrm{~K}$, resulting in lower

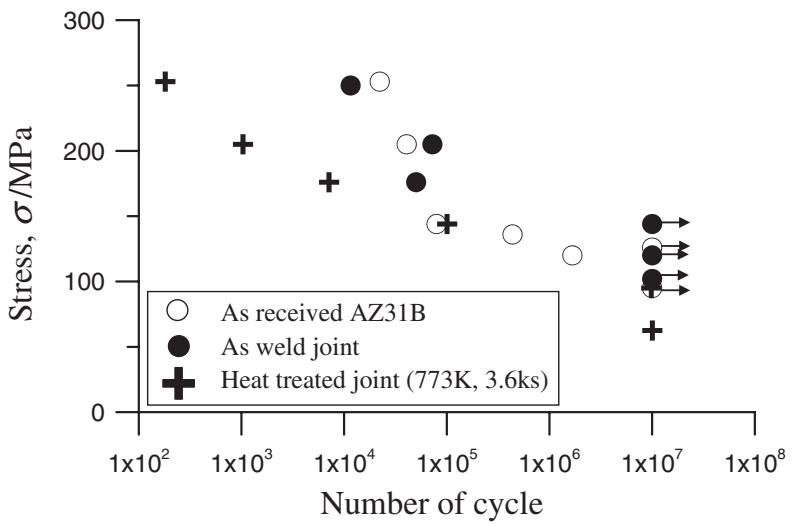

Fig. 11 Fatigue property of as received AZ31B alloy, as-weld joint and heat treated joint.

tensile strength than that of base metal despite almost similar grain size to base metal. Since most joints were fractured not at the weld interface, the relation between mean grain size and tensile strength was not evaluated exactly.

Figure 11 shows the results of fatigue tests. The fatigue strength at $1 \times 10^{7}$ of as weld joint was equal to that of base metal. However, heat treated joints that have similar grain size to base metal showed lower fatigue limit than that of base metal or as weld joint. This is because the effect of either work hardening or grain refinement did not work after heat treatment for fatigue strength as well as tensile strength. Further works must be necessary to investigate the effect of PWHT on fatigue properties.

\section{Discussion}

Several studies on the relation between grain size and strength such as hardness, tensile strength and yield strength of magnesium and magnesium alloys have been reported. It is well known classical Hall-Petch relation which shows linear relation of strength against (grain size: $d)^{-0.5}$ is found on most metals. However, magnesium alloys sometimes show non-linear relation between grain size and strength in the range of small grain size. ${ }^{14)}$ AZ31B magnesium alloys with various grain size could be fabricated by adequate heat treatment following friction welding as described above as much as the controlled area is very limited. Figure 12 shows effect of grain size on micro Vickers hardness and yield strength of AZ31B magnesium alloy. Vickers hardness, $0.2 \%$ proof stress and grain size were measured at the weld center. The smallest grain size of $1.1 \mu \mathrm{m}$ in Fig. 12 was found in the

Table 2 Effect of PWHT on tensile properties of friction welded joint.

\begin{tabular}{lccc}
\hline & $\begin{array}{c}\text { Tensile } \\
\text { strength }(\mathrm{MPa})\end{array}$ & $\begin{array}{c}0.2 \% \text { proof stress } \\
\text { at weld interface }\end{array}$ & $\begin{array}{c}\text { Mean grain size } \\
\text { at weld interface }\end{array}$ \\
\hline As received AZ31B & 278.1 & 219 & 17.8 \\
As weld joint & 281.7 & 135.5 & 1.3 \\
$473 \mathrm{~K} / 1.8 \mathrm{ks}$ & 281.1 & 135 & 1.6 \\
$573 \mathrm{~K} / 0.8 \mathrm{ks}$ & 281.9 & 141.5 & 3.3 \\
$573 \mathrm{~K} / 1.8 \mathrm{ks}$ & 281.9 & 100 & 6.4 \\
$773 \mathrm{~K} / 3.6 \mathrm{ks}$ & 260.7 & 82 & Base metal metal metal \\
\hline
\end{tabular}



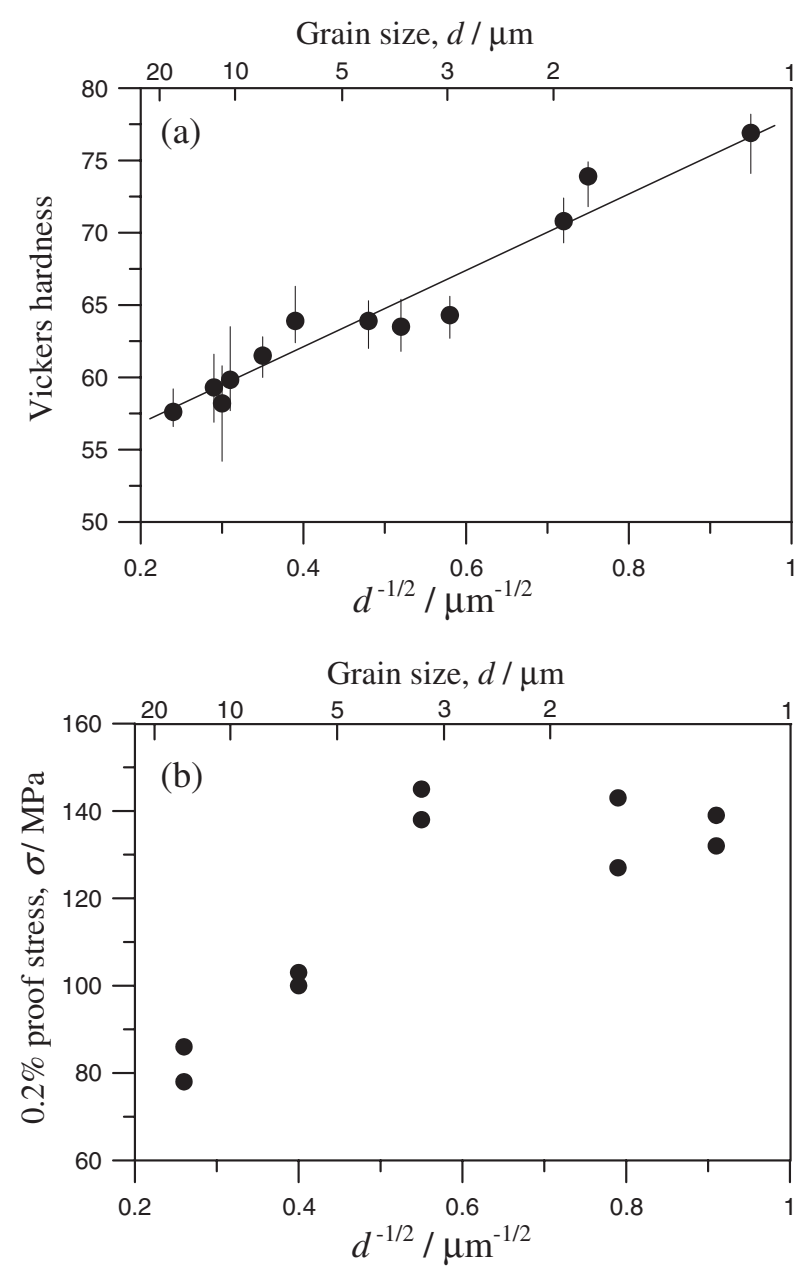

Fig. 12 Effect of grain size on (a) micro Vickers hardness, and (b) $0.2 \%$ proof stress.

as weld joint. (see Fig. 8) It should be noted again that recrystallized fine grains at the center of weld interface formed by friction welding contain few dislocations, ${ }^{9,10,18)}$ which is much less than that in stir zone by FSW. ${ }^{1)}$ The grains in heat treated joints would also contain few dislocations. Therefore, the effect of work hardening must be negligible in Fig. 12. Vickers hardness showed good linear relation against the $d^{-0.5}$ as well as previous reports. ${ }^{10)}$ Xing et al. and Park et al. also found Hall-Petch relation against hardness for magnesium alloys. ${ }^{1,19)}$ Although literature ${ }^{1)}$ is the study on a friction stir zone with a high dislocation density, Hall-Petch relation is realized for at least hardness. On the other hand, different results were reported in terms of yield strength. Wilson reported yield stress of magnesium increase with decreasing grain size up to $3-4 \mu \mathrm{m}$, and decreased after reaching the peak value. ${ }^{14)}$ Nussbaum et al. reported yield stress of AZ91 alloy increased linearly with increasing $d^{-0.5} .^{20)}$ However, in their study, the effect of precipitates would not be negligible as they mentioned. In the present study, the effect of grain size on yield stress is similar to the literature. ${ }^{14)}$ In general, it is hard to be found a HallPetch form in wide range of grain size from nano-crystalline to large grains. Because multislip is activated in the grain boundary regions, whereas grain interiors are initially dominated by single slip. So at large grain sizes, it has the
Hall-Petch form, and in the nanocrystalline region the slope gradually decreases until it asymptotically approaches the flow stress of the grain boundaries. ${ }^{21)}$ Especially, the tendency might be more remarkable for $\mathrm{Mg}$ which has $h c \mathrm{p}$ crystal structure than the other cubic metals. The major deformation mechanism of magnesium is based on a basal slip, resulting in less formability than cubic metals. That is to say, basal $a$ dislocation is dominant factor for deformation in grain interior. However, non-basal $a$ dislocation is active near grain boundaries. When the grain size is less than $7 \mu \mathrm{m}$, not only basal $a$ dislocation but also non-basal $a$ dislocations are activated, resulting in better deformation. ${ }^{22)}$ The mechanism illustrates the results in the present study.

\section{Summary}

The effect of post weld heat treatment on microstructures and mechanical properties of friction welded joints of magnesium alloy was investigated. Fine grained regions, work hardened region and heat affected zone were formed continuously from weld interface to base metal by friction welding. The minimum grain size of $1.1 \mu \mathrm{m}$ was obtained at the center of weld interface. Although abnormal grain growth occurred at work hardened regions, normal grain growth was found at the center of weld interface by PWHT. Tensile strength and fatigue strength of as weld joints were equal to that of base metal. The effect of PWHT on the mechanical properties was most likely negligible until grain size increased to approximately $15 \mu \mathrm{m}$.

The decrease in the Hall-Petch slope was found when the grain size decreased less than $3 \mu \mathrm{m}$ in grain size in terms of yield stress.

\section{Acknowledgements}

The authors wish to thank Seimitsu Kogyo LTD. for their technical assistance. The authors also thank Mr. S. Mizuno for his experimental assistance.

\section{REFERENCES}

1) S. H. C. Park, Y. S. Sato and H. Kokawa: J. Mater. Sci. 38 (2003) 43794383.

2) W. B. Lee, Y. M. Yeon and S. B. Jung: Mater. Sci. Technol. 19 (2003) 785-790.

3) Y. S. Sato, S. H. C. Park and H. Kokawa: Metall. Mater. Trans. A 32A (2001) 3033-3042.

4) L. Liu, H. Nakayama, S. Fukumoto, A. Yamamoto and H. Tsubakino: Mater. Trans. 45 (2004) 288-291.

5) K. N. Krishnan: J. Mater. Sci. 37 (2002) 473-480.

6) A. Goloborodko, T. Ito, X. Yun, Y. Motohashi and G. Itoh: Mater. Trans. 45 (2004) 2503-2508.

7) T. H. Hazlett and K. K. Gupta: Weld. Res. Suppl., Nov. (1963), 490s494s.

8) Y. Oue, K. Okita, M. Aritoshi and H. Nakayama: Proc. 6th Inter. Fatigue Congress, FATIGUE '96, 3 (1996) 1849-1854.

9) S. Fukumoto, H. Tsubakino, T. Tomita, M. Aritoshi and K. Okita: Mater. Sci. Technol. 18 (2002) 219-225.

10) S. Fukumoto, S. Tanaka, T. Ono, H. Tsubakino, T. Tomita, M. Aritoshi and K. Okita: Mater. Trans. 47 (2006) 1071-1076.

11) T. Rich and R. Roberts: Weld. Res. Suppl., March (1971) 137s-145s.

12) C. J. Cheng: Weld. Res. Suppl., Dec. (1962) 542s-550s.

13) K. K. Wang and P. Nagappan: Weld. Res. Suppl., Sept. (1970) 419s- 
$426 \mathrm{~s}$.

14) D. V. Wilson: J. the Institute of Metals 98 (1970) 133-143.

15) Kh. A. A. Hassan, A. F. Norman, D. A. Price and P. B. Prangnell: Acta Mater. 51 (2003) 1923-1936.

16) Y. S. Sato, H. Watanabe, S. H. C. Park and H. Kokawa: 5th Inter. Symp. friction stir welding, Metz, France, 14-16 September 2004, CD-ROM.

17) T. Shibayanagi, M. Maeda and M. Naka: J. JILM 56 (2006) 347-353 (Japanese).

18) I. Masumoto and H. Hira: Quarterly J. Japan Wedl Soc. 48 (1979) 1001-1005 (Japanese).
19) J. Xing, H. Soda, X. Yang, H. Miura and T. Sakai: J. Japan Inst. Light Metals 54 (2004) 527-531 (Japanese).

20) G. Nussbaum, P. Sainfort and G. Regazzoni: Scr. Metall. 23 (1989) 1079-1084.

21) H.-H. Fu, D. J. Benson and M. A. Meyers: Acta. Mater. 49 (2001) 2567-2582.

22) T. Kobayashi, J. Koike, Y. Yoshida, S. Kamado, M. Suzuki, K. Maruyama and Y. Kojima: J. Japan Inst. Metals 67 (2003) 149-152 (Japanese). 